Original Research Article

\title{
Pharmacoeconomic evaluation in cost of illness in type 2 diabetes mellitus patients in a tertiary care hospital
}

\author{
Tushar R. Bagle ${ }^{1}$, Vijay A. Vare ${ }^{1 *}$, Alankar Nimgade ${ }^{2}$, Rohan C. Hire ${ }^{1}$, Yogesh Sharma ${ }^{3}$, \\ Prasita Kshirsagar $^{3}$
}

${ }^{1}$ Department of Pharmacology, ${ }^{2}$ MBBS Medical Student, ${ }^{3}$ Department of Medicine, RGMC and CSMH, Kalwa, Thane, Maharashtra, India

Received: 13 September 2017 Accepted: 18 September 2017

*Correspondence to:

Dr. Vijay A. Vare,

Email: drvijayvare25@

gmail.com

Copyright: () the author(s), publisher and licensee Medip Academy. This is an openaccess article distributed under the terms of the Creative Commons Attribution NonCommercial License, which permits unrestricted noncommercial use, distribution, and reproduction in any medium, provided the original work is properly cited.

\begin{abstract}
Background: India is expected to bear the burden of world's greatest increase of diabetes population. This burden needs to be considered in terms of costs.

Methods: Cross-sectional study was done in type 2 diabetes mellitus 100 patients that attended Medicine OPD. Prior to enrollment Institutional Ethics Committee permission was taken. Written Informed consent was taken. Demographic information related to Education, Occupation and Income was taken down. Also Information related to diagnostic tests and medications were documented. Inclusion criterion were 18-70 years of either gender diagnosed by Physicians in OPD as type 2 diabetes, willing to participate and have followed in OPD for at least one year. The Exclusion criterion was Critically ill or unconscious patients and Pregnant women. Direct and indirect costs were calculated.

Results: The average age was $56.31 \pm 10.50$ years. The average fasting blood glucose was $120.65 \pm 22.70 \mathrm{mg} / \mathrm{dl}$. The average cost per month for investigations was $159.74 \pm 128.06$. Annual visit to OPD was $13.06 \pm 7.35$. Time loss per visit was $5.62 \pm 1.29$ hours and of accompanying person was $6.55 \pm 3.87$ hours. There were 2 from Lower and 63 from Upper Lower socioeconomic class. There were 41 patients having diabetic complications. The indirect cost was around 5838.51 and direct cost was around 19925. Total cost per annum per patient was around 32361.27 INR.

Conclusions: There is need for strategies to reduce the cost burden. There is also needed to design financial systems for diabetes related nationwide health programs.
\end{abstract}

Keywords: Direct costs, Glibenclamide, Indirect costs, Metformin, Pioglitazone, Voglibose

\section{INTRODUCTION}

Diabetes mellitus (DM) is a metabolic disorder having pathophysiology of insufficient release of insulin or resistance to action of insulin or both. Diabetes is broadly classified as type 1 diabetes in which there is absolute deficiency of insulin, and type 2 diabetes (T2DM) caused by reduced insulin secretion and resistance to insulin. ${ }^{1}$

According to International diabetes federation (IDF) atlas 2015, there were 415 million people in 2015 worldwide having DM and is estimated to reach 642 million by 2040 .
Nearly $80 \%$ of the world's diabetic patients are from low and middle-income countries. In the World, India is second country having largest number of diabetic people with 65.1 million in 2015 and expected to reach 109 million by 2035 . In coming decades India has to bear the burden of world's greatest increase of diabetic patients. ${ }^{2,3}$

The health burden of diabetes mellitus in India is raggedly distributed across various socioeconomic population. ${ }^{4,5}$ This burden in Indian population can be evaluated by estimating health care costs. ${ }^{6}$ The global health spending on diabetes was estimated around 673 billion United States 
Dollars (USD) in 2015 and expected to reach 802 USD billion in 2040. ${ }^{2}$ T2DM is a chronic disease with characteristics of hyperglycemia, dyslipidemia and progresses to microvascular and macrovascular complications seen progressively in long duration. ${ }^{7}$

Knowledge of costs related to diabetes helps to improve understanding, addressing health care and prevention issues associated with diabetes. The upcoming challenge for researchers on diabetes is to study alternative intercessions for management of diabetes. This is limited by sparse data on health expenditure costs especially in T2DM patients. ${ }^{8}$ Thus the present study was planned to evaluate the health care expenditure by evaluating the direct costs and indirect costs in T2DM patients in a tertiary care hospital.

\section{METHODS}

A Cross-sectional Randomized study was done at tertiary care medical college and hospital in a metropolitan city in 100 diabetic patients attending Medicine OPD of a tertiary care hospital. The confidentiality of the volunteers was maintained throughout the study. The duration of study was from 01 April 2016 to 30 May 2017. The patients were explained about the purpose and methodology of the study in language patient understands and Informed consent was administered prior to enrollment. Demographic information of the patients was noted in separate annexure. The socioeconomic status was evaluated by Education, Occupation and Income parameters noted according to Kuppuswamy's Socio Economic Status Scale in separate annexure. ${ }^{9}$ Information related to the medications was documented. Information with respect to the different diagnostic test related to diabetes were documented.

The Inclusion criterion was patients of 18-70 years of age and either gender, diagnosed by Physicians in Medicine OPD as type 2 diabetes according to American Diabetes Association (ADA) guidelines. ${ }^{10}$ The patients that followed in Medicine OPD for at least one year and were willing to participate in the study were included. The exclusion criterion were Critically ill or unconscious patients, Pregnant women and Type I diabetes mellitus patients. Those patients that were not willing to participate or not willing to give the details related to the study questionnaire were excluded.

The direct costs were calculated that included costs of visits to specialists, pharmaceutical and device, laboratory and diagnostic tests, if any comorbid conditions than additional costs for each comorbid condition, also if any complications related to diabetes than additional costs for each complication was calculated. The total cost was estimated by multiplying the number of each care unit by unit costs of each type of care and the resulting total cost was annualized. The Indirect Cost calculated included expenditures such as food, transportation of accompanying family members. ${ }^{11,12}$
CIMS (Current Index of Medical Speciliaties) and IDR (Indian drug review) 2017 issues were reviewed for prices of drugs used in the management of diabetes mellitus. The cost of medicines used for diabetes manufactured by different companies was estimated on the basis of medicines having the same strength and dosage form. ${ }^{13,14}$ The difference in the maximum price and minimum price of the medicine used for diabetes manufactured by different companies was calculated. The formula for calculating variation in percentage of price was calculated by following formula. ${ }^{15}$

\section{The Price of most expensive brand - The Price of least expensive brand X 100}

The Price of least Expensive brand.

All the costs were calculated in terms of Indian Rupees (INR).

\section{Statistical analysis}

Descriptive statistics was being used to identify the personal characteristics of the total respondents. $\mathrm{P}$ value $<0.05$ was considered for statistically significance. Data was entered in MS Excel 2010 and responses were coded and analyzed. Data was expressed in actual number, frequency, percentage, mean \pm standard deviation. Chi square and Fishers test was used for Categorical values. Parametric tests were used to compare the scores among subgroups. Graphpad 5.0 version was used for statistical analysis.

\section{RESULTS}

The average age in our study was $56.31 \pm 10.50$ years (range 23 to 68 years). There were 40 females and 60 males. Among the 100 patients, 97 were from urban area and three from rural area. Among the Socioeconomic status there were 2 from Lower SEC, 63 from Upper Lower SEC, 27 from Lower Middle and 8 from Upper middle. Out of 100, 40 patients were accompanied by relatives that included wife (13), husband (9), daughter (10), Son (6), Brother (1), Sister (2), and Neighbor (2). Out of 100 patients 37 travelled to hospital by rickshaw, 12 by train, 13 by bus, 14 by train and rickshaw, 7 by walking, 4 by bus and rickshaw, 11 by bus and train. The average cost to patient per visit for travelling was $89.45 \pm 63.67$ (INR). Time loss of the patient in hours per visit was $5.62 \pm 1.29$ hours and of the accompanying person was $6.56 \pm 3.87$ hours. Others include costs of needles, syringes, cotton, diabetic footwear etc. The direct costs are given in Table 1 and indirect costs are given in Table 2.

The average frequency for Laboratory visit was $10.9 \pm 4.61$ per year. The average cost per month for laboratory investigations was $159.74 \pm 128.06$. HbA1c was done only by seven patients. The average fasting blood glucose was $120.65 \pm 22.70 \mathrm{mg} / \mathrm{dl}$. The gender differences are given in Table 3 . 
Table 1: Direct medical costs.

\begin{tabular}{|ll|}
\hline Direct costs & Indian rupees (yearly) \\
\hline Consultation & 2567 \\
\hline Admissions for complications & 7650 \\
\hline Laboratory tests & 1908.6 \\
\hline Home tests & 5780 \\
\hline Medicines & 10380 \\
\hline Travel Costs & 1121.16 \\
\hline Alternative medicines & 1360 \\
\hline Others & 1756 \\
\hline Total & 26522.76 \\
\hline
\end{tabular}

Table 2: Indirect medical costs.

\begin{tabular}{|ll|}
\hline Indirect costs & Indian rupees (annually) \\
\hline $\begin{array}{l}\text { Transportation of } \\
\text { accompanying person }\end{array}$ & 1362.48 \\
\hline $\begin{array}{l}\text { Food and other } \\
\text { miscellaneous expenses }\end{array}$ & 4476.03 \\
\hline Total & 5838.51 \\
\hline
\end{tabular}

Table 3: Comparison of male and female gender.

\begin{tabular}{|llllll|}
\hline \multirow{2}{*}{ Parameters } & Female & & Male & & P \\
& Mean & SD & Mean & SD & Value \\
\hline Age & 53.19 & 9.53 & 56.31 & 8.91 & 0.103 \\
\hline FBG & 126.70 & 25.62 & 114.61 & 19.79 & 0.013 \\
\hline Lab tests & 173.56 & 32.67 & 179.74 & 34.91 & 0.369 \\
\hline Visits & 11.50 & 2.47 & 13.06 & 2.56 & 0.002 \\
\hline Time loss & 4.43 & 1.68 & 5.62 & 1.83 & 0.001 \\
\hline $\begin{array}{l}\text { Accompanying } \\
\text { person }\end{array}$ & 5.97 & 1.79 & 6.55 & 2.07 & 0.139 \\
\hline
\end{tabular}

The comorbidities associated with diabetic patients were 81 (Female $(\mathrm{F}): 32$ Male $(\mathrm{M}): 49,[\mathrm{P}=0.83]$ ) patients for hypertension, 65 (F:36, M:29 [p<0.0001]) had arthritis, 41 (F:18, M:23 [0.072]) had hyperlipidemia. Among 100 patients 31 patients had complications of diabetes, out of this 11 had diabetic foot, 9 had diabetic nephropathy, 8 had diabetic neuropathy and 3 had diabetic retinopathy. Other serious complications were 21 had suffered from hypoglycemia, 03 patients had suffered from diabetic ketoacidosis, 04 from foot amputation while 04 had previous history of myocardial infarction.

Table 4: Percentage variability in diabetic medications.

\begin{tabular}{|llllll|}
\hline Diabetic medications & Dose & Minimum & Maximum & Difference & Percentage variation \\
\hline Metformin & $1 \mathrm{~g}$ & 6.4 & 59 & 52.6 & 821.88 \\
\hline Metformin + Gliclazide & $500 \mathrm{mg}+40 \mathrm{mg}$ & 15 & 78 & 63 & 420.94 \\
\hline Glimeperide & $1 \mathrm{mg}$ & 11.5 & 73.95 & 62.45 & 543.04 \\
\hline Glibenclamide & $2.5 \mathrm{mg}$ & 3.6 & 6.5 & 2.9 & 833.33 \\
\hline Pioglitazone & $15 \mathrm{mg}$ & 12 & 112 & 100 & 833.33 \\
\hline Human Mixtard & $40 \mathrm{IU} / \mathrm{ml}$ & 118 & 217 & 99 & 83.89 \\
\hline Acarbose & $50 \mathrm{mg}$ & 70 & 117 & 47 & 67.14 \\
\hline Voglibose & $0.2 \mathrm{mg}$ & 31 & 102 & 71 & 229.03 \\
\hline
\end{tabular}

Annual visit to OPD was $13.06 \pm 7.35$ times. Other than the current OPD, patients also visit other OPDs like, Private Medicine OPD (16), Ophthalmology (15), Orthopedic (13), Surgery (4) and Gynecology (3). 56\% of the patients used only Metformin, 31\% used Metformin as combination with other medicines (Gliclazide, Glimeperide, Glibenclamide, Acarbose, Voglibose, Pioglitazone), $8 \%$ Glibenclamide, 5\% used Glimeperide. The percentage variability in diabetic medications is given in Table 4.

\section{DISCUSSION}

Diabetes is a chronic disorder of endocrine and metabolism which requires a life-long therapy. ${ }^{16}$ Since diabetes is a chronic disease associated with comorbidities and complications, it has a substantial impact on the cost of care. ${ }^{17}$ India is home to the second largest number of adults living with diabetes worldwide, after China, but still India spent less than $3 \%$ of the global total (ID23 billion) costs on diabetes. ${ }^{2}$

In our study average age was $56.31 \pm 10.50$ years and $60 \%$ of the patients were males. Study by Assefa had $130 \mathrm{DM}$ patients, of which $51.54 \%$ were females and $48.46 \%$ were males. ${ }^{1}$ Study by Chidambaram had $67.5 \%$ males and $32.5 \%$ were females. ${ }^{18}$ Study by Abdelaziz had 62 patients in the study with majority of the patients in 40-60 years with mean age of $64 \pm 12$ years. Similar results were found by other studies like Davari. ${ }^{19}$

In the present study majority of the patients had uncontrolled FBG. FBG of females was more than males. Visits to the OPD were more by male patients than females in a year. Time loss by male patients was more than females and was statistically significant. In our study, Medicines followed by admissions for complications 
contributed to majority of the direct costs. In study by Prajapati the mean total cost was 12391.84 (INR). Contributions from direct medical cost were $74 \%$, direct non-medical cost were $2 \%$ and indirect were $24 \% .{ }^{17}$ Study by Chidambaram, average per patient annual direct cost was 38,589 (INR). ${ }^{18}$ Study by Sortso had 14,349 Euros per patient-year. $^{21}$

According to study by Prajapati, maximum cost incurred was due to diabetic medicines $(44.14 \%)$ followed by admissions due to complication cost $(43.34 \%)$. Out of total 90 diabetic patients, $47.78 \%$ patients, developed one or more diabetic complications. 27 (30\%) patients need hospitalization during their one year follow up period. Medicine cost was a major contributor in any cost of illness study. $1.5 \%$ of the total diabetic cost was contributed by cost of alternative medicines, cost of home monitoring and cost of syringes, needles and cotton. ${ }^{17}$ According to study by Abdelaziz direct cost ranged from 3,350 to 22,183 (INR). ${ }^{19}$

Study by Assefa, 11530.68 USD was the cost of illness of diabetes in 2012 and per patient/year was 88.70 USD. Among these $73.10 \%$ was on medicine costs. The cost of illness in patients with complications was USD 125 and significantly higher than without complications that was USD 76. Numbers of visits to DM clinic, type of DM and residence area were found to affect the cost significantly. ${ }^{1}$ According to study by Chidambaram the average direct annual cost for type 2 diabetes was 38,589 (INR). ${ }^{18}$

In our study, the maximum variation in percentage was for Glibenclamide and Pioglitazone followed by metformin. According to study by Sortso cost of illness due to diabetes was classified as that with no complication (6,254 EUR), minor complication (14,164 EUR) and major complication (32,386 EUR) per person-year. ${ }^{21}$ In study by Suleiman Hypertension was concurrent illness in almost $83.78 \%$ of the patients. $^{22}$ According to Study by Davari, diabetic Nephropathy (72.4\%), and neuropathy (39\%) were the most frequent complications seen in diabetic patients. ${ }^{20}$

According to study by Abdelaziz 56\% of the patients were receiving metformin monotherapy and metformin with glimipiride as combination drug by $30 \% .{ }^{19}$ According to study by Shah, among the medicines prescribed for diabetes, Metformin was commonly prescribed and Sitagliptin was costliest prescribed medicine. ${ }^{16}$

Study by Shah found Metformin had price variation of $94.83 \%$ and of Sitagliptin was $174 \% .^{16}$ In study by Chincholkar, found about $3012 \%$ price variation for Metformin (500mg), 2809\% for combination of Voglibose $(0.3 \mathrm{mg})+$ Metformin $(500 \mathrm{mg})$, there was huge price variation in cost of oral antidiabetic medications. ${ }^{23}$ Study by Jadhav had Metformin (500mg) and Pioglitazone $(15 \mathrm{mg})$ that showed maximum price variation of $308.33 \%$ and $542 \%$ respectively. In combination therapies, Glipizide and Metformin combination showed the maximum variation up to $399.04 \% .{ }^{15}$ Similarly study by
Hussain had Glipizide 5mg that showed variation of $780 \%$ and Pioglitazone $15 \mathrm{mg}$ showed variation of $600 \%$. Glimepiride $1 \mathrm{mg}+$ Metformin 500mg combinations showed price variation of $533 \% .{ }^{24}$ Similar results were there in study by Selva. ${ }^{25}$ Thus for medicines prescribed for type 2 diabetes there was high percentage variation in our study and was also shown by other studies.

HbA1c was done only by seven patients in our study, While $\mathrm{HbA} 1 \mathrm{c}$ is the gold standard test around the world for insulin initiation and intensification but it is not easily available to a large section of Indian population. ${ }^{26}$

Literature review done by Yesudian had suggested that economic burden of diabetes can be reduced by improvement of universal healthcare coverage, improving the access to affordable medicines, and by early disease detection and treatments in OPD. ${ }^{27}$ While study by Solli had suggested Patient organizations might play a role in developing guidelines for cost of illness studies and in high cost illness like diabetes, costs to the society may be helpful in devoting resources to diabetes prevention and research. $^{28}$

Majority of the cost in diabetes is preventable through improved diet, exercise and prevention of diabetes should be initiated worldwide and nationwide. ${ }^{29}$ Thus knowing the cost will help in designing financial systems for diabetes related nationwide health programme. The health insurers, policy makers and other stakeholders could get a view and can form strategies to reduce the cost. Wide Percentage variations in medications need to be addressed. Importance of diabetes screening and prevention can be known in terms of cost effectiveness.

\section{Limitations}

The study was carried out in single center. As study was Cross sectional study there were higher chances of recall bias. Being a tertiary care Government hospital cost of medicines and physician visit were less.

Funding: No funding sources

Conflict of interest: None declared

Ethical approval: The study was approved by the Institutional Ethics Committee (RCMG/CSMH/IEC/Q/16/03/07 dated 09/03/2016)

\section{REFERENCES}

1. Assefa B, Wondimu A, Abrha S, Dinda SC, Demeke B, Samuel NG. Pharmacoeconomic evaluation of Antidiabetic treatment at Ayder Refrral Hospital, Mekelle, Ethiopia. Int. J. Pharm. Sci. Rev. Res. 2014;25(1):47-52.

2. International Diabetes Federation. IDF Diabetes, $7^{\text {th }}$ Ed. Brussels, Belgium: International Diabetes Federation, 2015. http://www.diabetesatlas.org. Available 
https://www.idf.org/sites/default/files/EN_6E_Atlas_ Full_0.pdf Accessed on 19 Jan 2016.

3. Kaveeshwar SA, Cornwall J. The current state of diabetes mellitus in India. AMJ. 2014;7(1):45-8.

4. Boyko EJ, Jacobson IJ, Smith B, Ryan MAK, Hooper TI. Gackstetter GD, et al. Risk of diabetes in US military service members in relation to combat deployment and mental health. Diabetes Care. 2010;33:1771-7.

5. Dray SR, Gary WT, Brancati FL. Educational disparities in mortality among adults with diabetes in the U.S. Diabetes care. 2010;33:1200-5.

6. Barcelo A, Aedo C, Rajpathak S, Robles S. The cost of diabetes in Latin America and the Caribbean. Bull World Health Organ. 2003;81:19-27.

7. Sobel BE, Schneider DJ. Cardiovascular complications in diabetes mellitus. Curr Opin Pharmacol. 2005;5:143-8.

8. Javanbakht M, Baradaran HR, Mashayekhi A, Kaghdoost AA, Khamesh ME, Kharazmi E. Cost of Illness Analysis of type 2 diabetes Mellitus in Iran. Plos One. 2011;6(10):e26864:1-7.

9. Park K. The Community: Socioeconomic scale. In: Park's Textbook of Preventive and Social Medicine. $23^{\text {rd }}$ Ed; India, Banarasidas Bhanot; 2015:689-690.

10. American Diabetes Association. Standards of Medical Care in Diabetes. (Position statement). Diabetes Care. 2014;37(1):14-80.

11. Köster I, Ferber LV, Ihle P, Schubert I, Hauner H. The cost burden of diabetes mellitus: the evidence from Germany- the CoDiM Study. Diabetologia. 2006;49:1498-504.

12. Barcelo A, Aedo C, Rajpathak S, Robles S. The cost of diabetes in Latin America and the Caribbean. Bulletin of the World Health Organization. 2003;81(1):19-27.

13. Aravind SR, Rao AC, Andrade C, Shetty DP, Geethamani V, Divaker H, et al. Current Index of Medical Specialties. UBM Medica India. Update 2. 2017:382-400

14. Aravind SR, Rao AC, Andrade C, Shetty DP, Geethamani V, Divaker H, Sharma JB et al. Indian Drug Review, Drug Triple Compedium. UBM Medica India. 2017;23(3):248-57.

15. Jadhav NB, Bhosale MS, Adhav CV. Cost Analysis Study of Oral Antidiabetic Drugs Available In Indian Market. Int J Med Res Health Sci. 2013;2(1):63-9.

16. Shah JV, Patni KN, Deshpande S. Pharmacoeconomic Evaluation, Cost Minimization Analysis of AntiDiabetic Therapy in Gujarat. International Journal of Medical Research \& Health Sciences. 2016;5(3):3443.

17. Prajapati A, Kothari N, Ganguly B. Economic burden of diabetes mellitus in western India - a hospital based study. Int J Basic Clin Pharmacol. 2016;5:2572-80.
18. Chidambaram D, Ajith AA, Sivagnanam TR. Cost- ofIllness Analysis of Type 2 Diabetic Patients in a Multispeciality Hospital at Coimbatore. Indian Journal of Pharmacy Practice. 2013;6(4):39-44.

19. Abdelaziz MS, Shobha RH, Ravindranath S, Ramjan S, Mohamed K, Anas AS. Pharmacoeconomic evaluation of oral-hypoglycemic agents at hospital in Bangalore. IOSR Journal of Pharmacy and Biological Sciences. 2015;10(5):46-50.

20. Davari M, Boroumand Z, Amini M, Aslani A, Hosseini M. The direct medical costs of outpatient cares of Type 2 diabetes in Iran: A retrospective study. Int J Prev Med. 2016;7:72.

21. Sortso C, Green A, Jensen PB, Emneus M. Research: Health Economics Societal costs of diabetes mellitus in Denmark. Diabetic Medicine. 2016;33:877-85.

22. Suleiman IA, Fadeke OF, Okubanjo OO. Pharmacoeconomic Evaluation of Anti-Diabetic Therapy in A Nigerian Tertiary Health Institution. Annals of African Medicine. 2006;5(3):132-7.

23. Chincholkar A, Pentewar G. Cost variation analysis of oral anti-diabetic agents available in drug store of the tertiary care hospital and in Indian market. Int J Basic Clin Pharmacol. 2017;6:1794-8.

24. Hussain S. Cost variation analysis of Oral Hypoglycaemic agents available in Indian market: An Economic Perspective. International Journal of Pharma Sciences and Research (IJPSR). 2015;6(5):913-8.

25. Selva P, Krishnan V. A study on cost analysis of various oral hypoglycemic Agents available in India. Int J Pharm Bio Sci. 2017;8(1):(B)13-7.

26. Kaveeshwar SA, Cornwall J. The current state of diabetes mellitus in India. Australasian Medical Journal. 2014;7(1):45-8.

27. Yesudian CAK, Grepstad M, Visintin E, Ferrario A. The economic burden of diabetes in India: a review of the literature. Globalization and Health. 2014;10(80):1-18.

28. Solli O, Jenssen T, Kristiansen IS. Diabetes: cost of illness in Norway. BMC. Endocrine Disorders. 2010;10:15.

29. Javanbakht M, Baradaran HR, Mashayekhi A, Haghdoost AA, Khamseh ME, Kharazmi E, et al. Cost-of-Illness Analysis of Type 2 Diabetes Mellitus in Iran. Plos One. 2011;6(10):1-7.

Cite this article as: Bagle TR, Vare VA, Nimgade A, Hire RC, Sharma Y, Kshirsagar P. Pharmacoeconomic evaluation in cost of illness in type 2 diabetes mellitus patients in a tertiary care hospital. Int J Basic Clin Pharmacol 2017;6:2334-42. 


\section{ANNEXURE I (INFORMED CONSENT)}

I have read the information given in the Informed Consent Document for this study titled

"Pharmacoeconomic evaluation in cost of illness in type 2 Diabetes Mellitus patients of India"

1. I have received an explanation of the nature, purpose, duration and expected effects of the study and what I will be expected to do.

2. I understand that my participation in the study is voluntary and that I may refuse to participate or may withdraw from the study anytime, without any penalty.

3. I agree not to restrict the use of any data or results that arise from this study provided such use is for scientific purpose only.

4. I understand that my identity will not be revealed in any publication.

5. I agree to take part in the above study.

Name of the participant Name of the person administering consent

Signature of the participant Signature of the person administering consent

Name of Legally Accepted Representative (LAR) Sign of LAR

Date of administering consent Date of administering consent 


\section{ANNEXURE II (DEMOGRAPHIC INFORMATION)}

1. Name (Optional)

2. Age (yrs)

3. Gender

4. Type of Diabetes

5. Duration of Diabetes

6. Address: Urban/Rural

7. Accompanying Relative: Relation

8. Mode of Transport to the OPD: Train/Bus/Rickshaw/Other

9. Total cost of transport

10. Laboratory Investigations done: Enumerate with frequency and cost

11. Documented Fasting blood glucose values from the last report

12. Asso. Co-Morbid Disease: Hypertension/Hyperlipidemia/Others

13. Complications: (D. Nepropathy/D. Retinopathy/D. Enteropathy/D. Foot/Others)

14. Annual Visits to OPD in last one year:

15. No. of Admissions in last one year due to diabetes:

16. No of OPD visits other than the current OPD:

If yes reasons:

17. Work absence

18. If accommodation, Cost of accommodation:

19. Time loss of patient

20. Time loss of accompanied person

21. Payment of paid caregivers 
ANNEXURE III (KUPPUSWAMY'S SOCIOECONOMIC STATUS SCALE)

Tick in the appropriate box

A. Education

\begin{tabular}{|l|l|l|l|}
\hline Sr. No & Education & Score & Tick \\
\hline 1 & Profession Of Honours & 7 & \\
\hline 2 & Graduate Or Postgraduate & 6 & \\
\hline 3 & Intermediate Or Post High School Diploma & 5 & \\
\hline 4 & High School Certificate & 4 & \\
\hline 5 & Middle School Certificate & 3 & \\
\hline 6 & Primary School Certificate & 2 & \\
\hline 7 & Illiterate & 1 & \\
\hline
\end{tabular}

B. Occupation

\begin{tabular}{|l|l|l|l|}
\hline Sr. No & Occupation & Score & Tick \\
\hline 1 & Profession & 7 & \\
\hline 2 & Semi profession & 6 & \\
\hline 3 & Clerical shop owner & 5 & \\
\hline 4 & Skilled worker & 4 & \\
\hline 5 & Semi-skilled worker & 3 & \\
\hline 6 & Unskilled worker & 2 & \\
\hline 7 & Unemployed & 1 & \\
\hline
\end{tabular}

C. Income

\begin{tabular}{|l|l|l|l|l|}
\hline Sr. No & Family Income per capita & Score & Modified FOR 2007 & Tick \\
\hline 1 & $=2000$ & 12 & $=19575$ & \\
\hline 2 & $1000-1999$ & 10 & $9788-19574$ & \\
\hline 3 & $750-999$ & 6 & $7323-9787$ & \\
\hline 4 & $500-749$ & 4 & $4894-7322$ & \\
\hline 5 & $300-499$ & 3 & $2936-4893$ & \\
\hline 6 & $101-499$ & 2 & $980-2935$ & \\
\hline 7 & $<100$ & 1 & $<979$ & \\
\hline
\end{tabular}

D. Total Score

\begin{tabular}{|l|l|l|}
\hline Total score & Socio economic class & Tick \\
\hline $26-29$ & Upper I & \\
\hline $16-25$ & Upper middle II & \\
\hline $11-15$ middle & Lower middle III & \\
\hline $5-10$ lower & Upper lower iv & \\
\hline$<5$ & Lower V & \\
\hline
\end{tabular}




\section{ANNEXURE IV (MEDICATIONS INFORMATION)}

Antidiabetic medications:

\begin{tabular}{|l|l|l|l|l|l|l|}
\hline Sr. No & $\begin{array}{l}\text { Generic } \\
\text { name of the drug }\end{array}$ & $\begin{array}{l}\text { Branded } \\
\text { name of the drug }\end{array}$ & $\begin{array}{l}\text { Frequency } \\
\text { of the drug }\end{array}$ & $\begin{array}{l}\text { Dose } \\
\text { of the drug }\end{array}$ & $\begin{array}{l}\text { Total } \\
\text { monthly cost }\end{array}$ & $\begin{array}{l}\text { Total } \\
\text { monthly cost }\end{array}$ \\
\hline 1 & & & & & & \\
\hline
\end{tabular}

Other medications:

\begin{tabular}{|l|l|l|l|l|l|l|}
\hline Sr. No & $\begin{array}{l}\text { Generic } \\
\text { name of the drug }\end{array}$ & $\begin{array}{l}\text { Branded } \\
\text { name of the drug }\end{array}$ & $\begin{array}{l}\text { Frequency } \\
\text { of the drug }\end{array}$ & $\begin{array}{l}\text { Dose } \\
\text { of the drug }\end{array}$ & $\begin{array}{l}\text { Total } \\
\text { monthly cost }\end{array}$ & $\begin{array}{l}\text { Total } \\
\text { monthly cost }\end{array}$ \\
\hline 1 & & & & & & \\
\hline
\end{tabular}

Medicines From Other Branches (Ayurvedic/Homeopathic/Unani/Other)

\begin{tabular}{|l|l|l|l|l|l|}
\hline Sr. No & $\begin{array}{l}\text { Branded } \\
\text { name of the drug }\end{array}$ & $\begin{array}{l}\text { Frequency of the } \\
\text { drug }\end{array}$ & Dose of the drug & Total monthly cost & $\begin{array}{l}\text { Total monthly } \\
\text { cost }\end{array}$ \\
\hline 1 & & & & & \\
\hline
\end{tabular}

Percentage Variability:

\begin{tabular}{|l|l|l|l|l|}
\hline Sr. No & Minimum cost & Maximum cost & $\begin{array}{l}\text { Difference between minimum and } \\
\text { maximum }\end{array}$ & $\begin{array}{l}\text { Percentage } \\
\text { variation }\end{array}$ \\
\hline 1 & & & & \\
\hline
\end{tabular}

